\title{
INVESTIGATING SOCIAL COGNITIVE THEORY IN ONLINE DISTANCE AND LEARNING FOR DECISION SUPPORT: THE CASE FOR COMMUNITY OF INQUIRY
}

(D) Ahmad Faiz
Ghazali $^{1+}$
(D) Ahmad
Kamalrulzaman
Othman
(D) Yusnita Sokman
(D) Noor Azrin
Zainuddin
(D) Aishah Suhaimi
(D) Nurkhairany
Amyra Mokhtar
(D) Rahmawati Mohd
Yusoff

Article History

Received: 25 August 2021 Revised: 29 September 2021 Accepted: 18 October 2021 Published: 11 November 2021

\section{Keywords}

Online distance learning (ODL) Social cognitive theory (SCT) Decision support system (DSS) Technology acceptance model (TAM)

\author{
${ }_{1,9,9,4,5,6,7,7}$ Universiti Teknologi MARA Cawangan Johor Kampus Segamat, Johor \\ Darul Ta'zim, Malaysia. \\ 'Email:faizghazali@uitm.edu.my
}

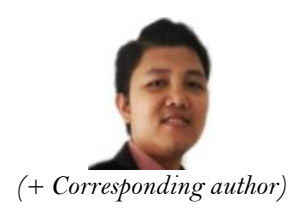

\begin{abstract}
Nowadays, students have learn to accept the reality of online learning. Therefore, this quantitative study aims to explore how behaviour and social factors can influence online learning. 203 participants responded to the instrument which is a survey. The findings show that the implication of online and distance learning (ODL) is to help students in getting to know each other as well as having the social, cognitive and situational presence. The instrument of teaching, social and cognitive presence based on Social Cognitive Theory (SCT) is measured in order to improve the management of ODL in university during post-COVID-19 pandemic. The first research question looks at how behaviour factors (social presence) influence online presence. Next the study also investigates how cognitive factors influence online presence. The final research question looks at how situational factors (teaching presence) influence online presence. In overall, ODL management in post-COVID-19 pandemic is expected to be more challenging than during or before the pandemic. The shift that happen caused a lot of physical, mental, and emotional responses from the teaching and learning community in general. Instrument teaching, social and cognitive presence are investigated thoroughly and interesting results found in this study is beneficial for future decision support system (DSS) development in the case for community of inquiry.
\end{abstract}

Contribution/ Originality: The contribution of this study is demonstrating the relation of social cognitive theory (SCT) which consists of behaviour, cognitive and situational factors portrayed through social, cognitive and teacher presence as a framework by case study of online and distance learning (ODL) for decision support in education during COVID-19 pandemic. 


\section{INTRODUCTION}

\subsection{Background of Study}

Online learning can be defined as instruction delivered on a digital device that is intended to support learning (Ferri, Grifoni, \& Guzzo, 2020). It also refers to the ability to use a computer connected to a network, which enables students to learn from anywhere, at any time, in any rhythm, and through any means (Dhawan, 2020). The term was also used to describe a tool that can improve the teaching and learning process by making it more studentcentered, innovative, and flexible (Dhawan, 2020). Furthermore, it actually can be referred as teaching and learning online, where educators and students teach and learn respectively using appropriate learning platforms (Yusuf \& Jihan, 2020). According to Ferri et al. (2020), online learning is associated with a variety of problems, including a lack of resources, such as access to educational technologies and the internet. Another recent study discovered that students struggled with issues such as lack of interaction with the instructor, response time, and a lack of traditional classroom socialization (Adnan \& Anwar, 2020). According to the instructor, students were less focused on online learning, and the platform or medium of learning was unsatisfactory. Several studies have also found that educators' unstable internet access disrupted the momentum of teaching, most likely resulting in students not attending online courses (Yusuf \& Jihan, 2020).

\subsection{Statement of Problem}

The problem addressed in this study is to investigate how online presence can be affected by the behaviour, cognitive, and situational factors. The aim is to integrate the model from Bandura (1977) and Arbaugh (2008) for the purpose of developing DSS in education. The COVID-19 crisis has forced education systems around the world to look for alternatives to traditional (face-to-face) learning. As a result, universities worldwide adopted online learning to avoid spreading the virus and also to ensure the continuity of the teaching and learning process (Ali, 2020).

Online learning offers flexibility and control over the learning experience whereby this helps in distant learning with easy administration and accessibility along with less use of resource and time (Fatonia et al., 2020; Hiranrithikorn, 2019; Mukhtar, Javed, Arooj, \& Sethi, 2020). In addition, online learning encourage studentcentered learning, whereby the students become self-directed learners, which is an important competency for encouraging lifelong learning (Mukhtar et al., 2020). Although online learning offers the convenience, flexibility, and ability to access classes remotely on the participant's own time; participants may feel isolated; because online learning is an individual act of joint activity, which may give the feeling that they are acting entirely on their own (Fatonia et al., 2020).

According to Hiranrithikorn (2019), online learning can result in low success rates, easy distraction, and lack of social interaction. Social interaction in online learning can increase student engagement and motivation while also helping to improve student performance. Fatonia et al. (2020) agreed that concentration serves as an important factor for academic success. Furthermore, due to the heavy workload, students endure stress as a result of online learning (Dewantoro \& Rachmawati, 2020; Maatuk, Elberkawi, Aljawarneh, Rashaideh, \& Alharbi, 2021). The majority of students were dissatisfied with the quantity of work they had to complete at home while studying. Besides, lecturers were unable to assess students' understanding during online lectures due to a lack of immediate feedback (Mukhtar et al., 2020). Hence, this study is done to explore interactions during online learning. This study explores how social cognitive theory is portrayed in online learning. .Specifically, this study is done to answer the following research questions;

(1) RQ1-How do behaviour factors influence online presence?

(2) RQ2-How do cognitive factors influence online presence?

(3) RQ3- How do situational factors influence online presence? 


\section{LITERATURE REVIEW}

\subsection{Introduction}

This section discusses factors that contribute to the success or failure of online learning, past studies related to online learning and also the conceptual framework of the study.

\subsection{What Makes Online Learning Effective?}

The effectiveness of online learning is influenced by many factors. Among the factors that influence the effectiveness of online learning are such as social interaction, academic skills, technical skills, student motivation, time and support from people around, technical problems, costs and access to the internet (Muilenburg \& Berge, 2005). Another possible factor that causes the lack of effectiveness of online learning is the design and arrangement of teaching materials that are less effective (Mayer, 2002).

A study by Baber (2020), show how important it is to study students' perceptions of online learning in an era of pandemics that are sweeping the globe. Perceptions by students that emphasize interaction, motivation, course content, and the role of the instructor are the main determining factors in producing good and positive quality of learning as well as affecting student satisfaction in the classroom. There is no denying that, good and positive learning outcomes through online learning, are illustrated by the high level of students' satisfaction despite being in challenging situations during the COVID-19 that is plaguing the world. The level of student achievement and satisfaction is an important factor in education that provides an overview of the impact on the transition of learning from offline to online. This shows that online learning failure is strongly influenced by student satisfaction.

Online learning has become a new norm and a routine thing among students nowadays. In fact, a large number of students around the world are already practicing it. Online learning encourages continuous growth in students' cognitive levels when students are actively involved in learning and increased the level of understanding in the classroom among students. However there are some unsatisfactory experiences experienced by students in online learning (Baloran, Hernan, \& Taoy, 2021). Factors contributing to this deficiency are, lack of communication and interaction between teachers and students which reduces the effectiveness of online learning. There are also situations where teachers are unable to understand the level of student engagement, especially the level of emotional engagement. Therefore, in an online learning environment, it is important for educators to evaluate and examine student engagement to identify students' level of understanding in the classroom. This can be realized by ensuring that students always take an active part in the learning sessions as well as giving them the opportunity to give their views and opinions openly under the control of the instructor.

\subsection{What Makes Online Learning Not Effective?}

Subramanian, Timberlake, Mittakanti, Lara, and Brandt (2012) determined that the format of online learning such as, feedback and guidance, matched task difficulties to students' developmental level and case-based teaching strategies designed, might have played a key role in improve the outcomes of online learning. But, for online learning that consisted of static, non-interactive learning resources that resembled by offline learning, usually no significant difference was found when compared to offline learning. Online learning might cannot be competing with some aspects of offline learning, like interactive knowledge building between teacher and students even though it could create opportunities for students to obtain self-learning abilities through information technology.

\subsection{Factors for Successful Online Learning}

The factors for successful online learning is including self-determination theory, besides social cognitive theory in ODL. Students are the stakeholders and the customers of a quality education. The behaviours or the attitudes of the students which are the customers must be observed as this is one of the important indicators for their behavior based on intention (Ajzeen, 2008). The online conversation can also help or not help them to investigate that 
perspective of doing works online. Stress, mental health or motivation issues can also become one of the main issues during ODL (Ghazali et al., 2020; Ghazali, 2021). The students' perception can influence their capability to study while facing challenges in tertiary institutions (Abbasi, Ayoob, Malik, \& Memon, 2020; Aboagye, Yawson, \& Appiah, 202 1; Agarwal \& Kaushik, 2020).

Mental model from DSS can be utilized for understanding students' underlying decision-making processes. Student's satisfaction in studying with online platforms was explored using DSS by Al-Rahmi et al. (2019). This is because by considering students' behaviour and acceptance in utilizing online platforms, Technology Acceptance Model (TAM) is proven as one of the most effective model. Their research looked into adaptive learning using DSS. One of the important role in TAM is that it detects the effects of other factors on attitudes and intentions (Davis, 1989). Perceived usefulness are among the important factors. Al-Rahmi et al. (2019) proposed a model to measure learning satisfaction in Malaysia using DSS in relation to TAM. However, the results obtained was representing the situation of adopting e-Learning in ODL before COVID-19 pandemic. Nevertheless, the origin of behaviour intention based on the assumptions in TAM is the process of conscious decision-making (Venkatesh, Morris, Davis, \& Davis, 2003). The feeling of good or bad from certain behaviour is know as the attitude towards usage in TAM (Rogers, 1995). Perceived usefulness and perceived ease-of-use are among the factors known as the cognitive factors. Long before the wide implementation of online learning, Tornatzky and Klein (1982) found that the students use the systems that are easy for them to use compared to the ones that are useful for them.

\subsection{Past Studies}

\subsubsection{Disadvantages of Learning Online}

There are past studies to show the disadvantages of online learning. According to Tareen and Haand (2020), the disadvantages of online learning include a lack of student interaction, an unclear assessment strategy, a lack of precise feedback and support from lecturers, and a lack of interest in learning. The instrument used was survey questionnaire, and the sample size is 30 participants from the Universiti Teknologi MARA, which are the students in Masters of Education. Kulal and Nayak (2020) conducted a study to examine the disadvantages of online learning. The instrument used was a structured questionnaire, and the sample included all graduate and postgraduate college students and instructors from various colleges in the Dakshina Kannada and Udupi Districts of Karnataka, India. According to the findings, instructors face challenges in conducting online lessons due to a lack of desirable education and development for establishing online classes. The main barrier to the effectiveness of online classes is technical issues.

\subsubsection{Advantages of Learning Online}

However, there are also past studies that have reported that online learning can provide (a) peer interaction and (b) flexibility. Peer interaction is a type of peer support in which students actively assist one another during the learning process. Through collaborative knowledge sharing, peer interaction can promote an active learning process. The study by Goh, Leong, Kasmin, Hii, and Tan (2017), was done to examine whether students' experiences in online learning are related to learning outcomes and satisfaction. A self-administered questionnaire was used to collect data from students who enrolled into online learning courses. 700 questionnaires were distributed to undergraduate students at a Malaysian university. According to the findings, peer interaction is the most important predictor of learning outcomes and satisfaction. This indicates that peer interaction is vital in an elearning course since it not only helps students learn, but also provides social emotional support in a computermediated learning environment. As a result, university administrators should acknowledge the importance of interactions in determining the quality of online learning.

Students benefit from the flexibility of online learning in terms of time, place, and pace of learning. The study by Kokoc (2019) was done to investigate how perceived flexibility affects behavioural engagement and academic 
performance in an online learning environment. A predictive correlational design was used to perform the research. The study included 119 higher education students who were engaged in a 15-week totally online course. The findings revealed that perceived time flexibility and perceived content flexibility had significant positive effects on behavioural engagement and academic achievement. The finding contributes to our knowledge of the importance of flexibility dimensions in online learning experiences and outcomes.

This is supported by a study conducted by Mukhtar et al. (2020) which looked into the perception of teachers and students about online learning modalities, its advantages, limitations, and recommendations. A qualitative case study was conducted from March to April 2020. Using maximum variance sampling, twelve academic members and twelve students from the University College of Medicine and University College of Dentistry in Lahore were invited to participate. This study interprets the perspectives of medical/dental students and faculty members, which showed that online learning is a flexible and effective method of teaching and learning, with the majority of them agreeing that it facilitates distance learning through easy administration and accessibility as well as the efficient use of resources and time. Students can effortlessly access the learning material regardless of time constraints.

\subsection{Conceptual Framework}

This study is rooted from the social cognitive theory by Bandura (1986) and online presence by Garrison and Arbaugh (2007).

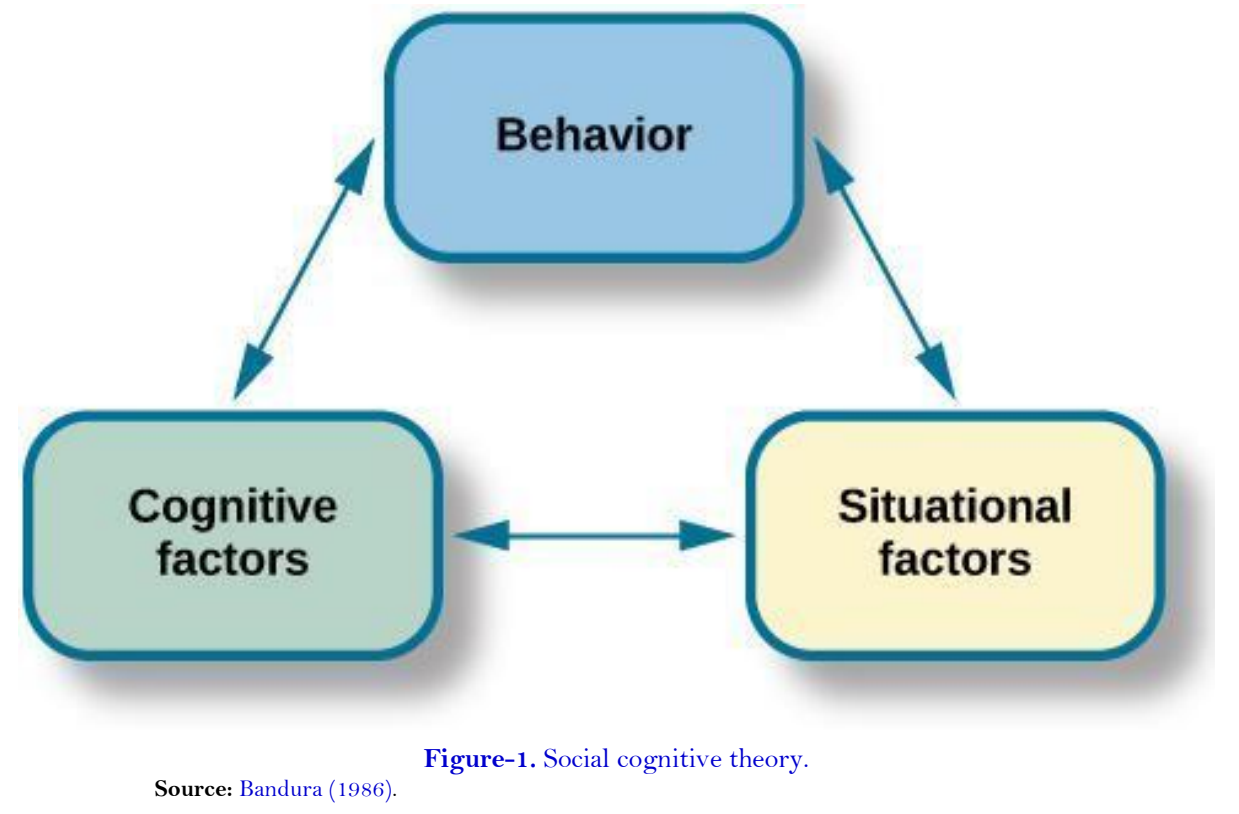

Figure 1 above presents how learning takes place according to the social cognitive theory by Bandura (1986). He states that learning is influenced by learners' situational factors around them. The situational factors can be influenced by what the teachers use (content and materials) in the learning process. These situational factors in turn influence the learners' cognitive factors. The conceptual framework Figure 2 of this study is built on the main theory of Bandura (1986) scaffolded onto online presence by Garrison and Arbaugh (2007).

In online learning, the situational factors also include the online learning environment. In the online learning environment, the teachers' presence can influence the environment of the online learning. Next, the situational factors can influence and be influenced by the behaviours of learning.

In online learning, the behavioural factors are portrayed by the social presence that is evident in the online class. The combination of situational and behavioural factors can then influence the cognitive factors of the learners. 
BEHAVIOURAL FACTOR

(PORTRAYED THROUGH

SOCIAL PRESENCE)

COGNITIVE FACTORS

(PORTRAYED THROUGH

COGNITIVE PRESENCE
SITUATIONAL FACTORS

(PORTRAYED THROUGH

TEACHER PRESENCE)

Figure-2. Conceptual framework for the community of inquiry of the study. Source: Bandura (1986) \& Garrison and Arbaugh (2007)

\section{METHODOLOGY}

This quantitative study is done to investigate how learners perceive online learning, 203 participants responded to the instrument Table 1 which is a survey adapted from Garrison and Arbaugh (2007). It has 4 sections including the demographic profile. Section B has 13 items on teaching presence, section C has 9 items on social presence while section D has 12 items on cognitive presence.

Table-1. Distribution of items in survey.

\begin{tabular}{c|c|c}
\hline Section & Presence & Items \\
\hline B & Teaching & 13 \\
\hline C & Social & 9 \\
\hline D & Cognitive & 12 \\
\hline
\end{tabular}

Table-2. Reliability Statistics for the instrument.

\begin{tabular}{c|c}
\hline Cronbach's Alpha & N of items \\
\hline 0.975 & 34 \\
\hline
\end{tabular}

An analysis of the instrument revealed a Cronbach analysis of .975; thus showing a high internal reliability Table 2 for the instrument. Data is analysed using SPSS version 26 to reveal percentage and mean score for the demographic profile and the constructs respectively.

\section{FINDINGS}

This section presents findings for the data. The demographic profile is presented in the form of pie charts. The next sections reveal the data analysis to answer the research questions.

Q1.Gender

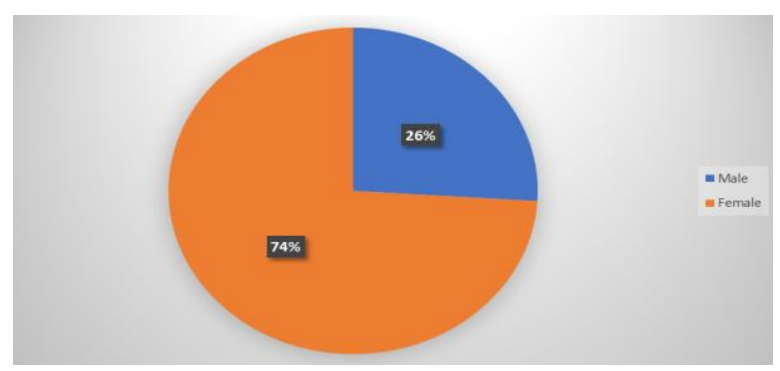

Figure-3. Percentage for gender. 
4.1. Findings for Demographic Profile

According to Figure 3 above, $74 \%$ are female respondents and the balance $74 \%$ are male.

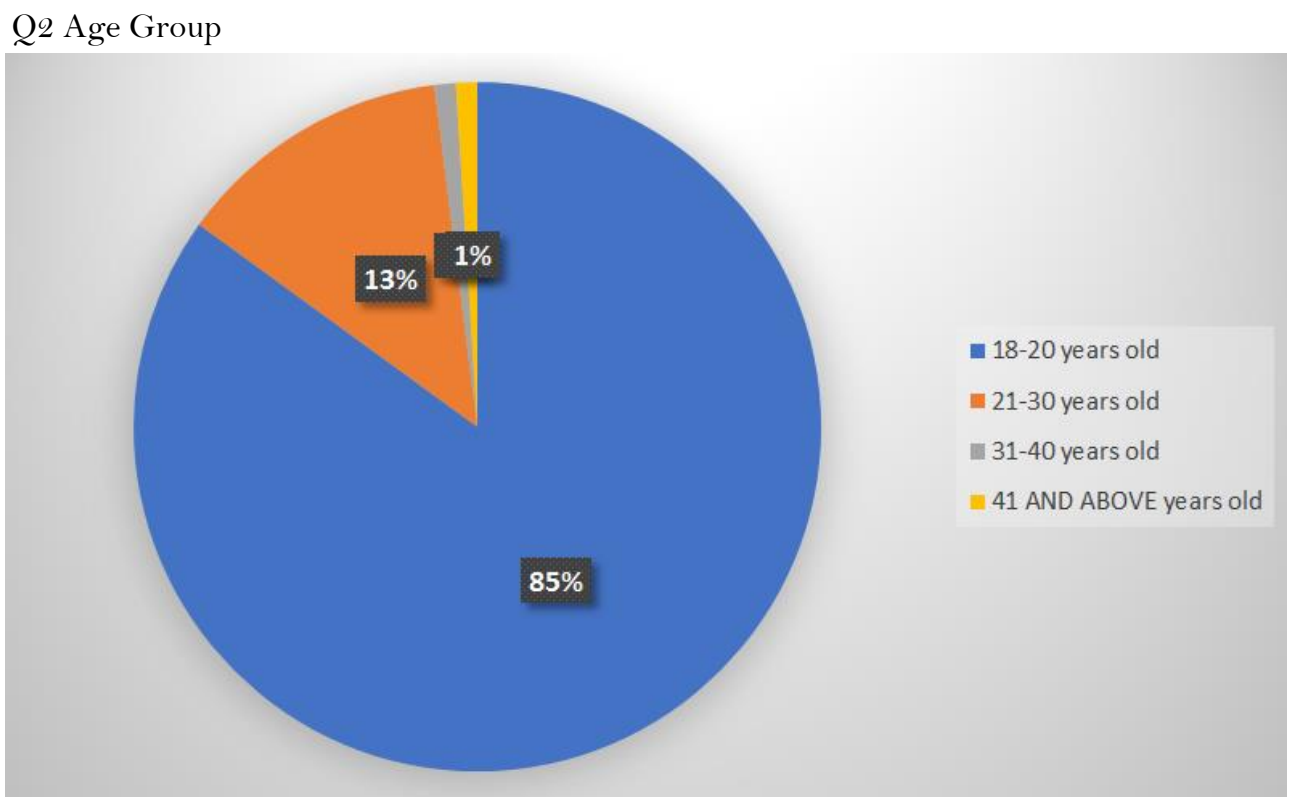

Figure-4. Percentage for age group.

For the age group in Figure 4, 85\% of respondents are aged 18-20 years. $13 \%$ were aged between 21 and 30 years, while only $1 \%$ were aged $31-40$ years and 41 years and above, respectively.

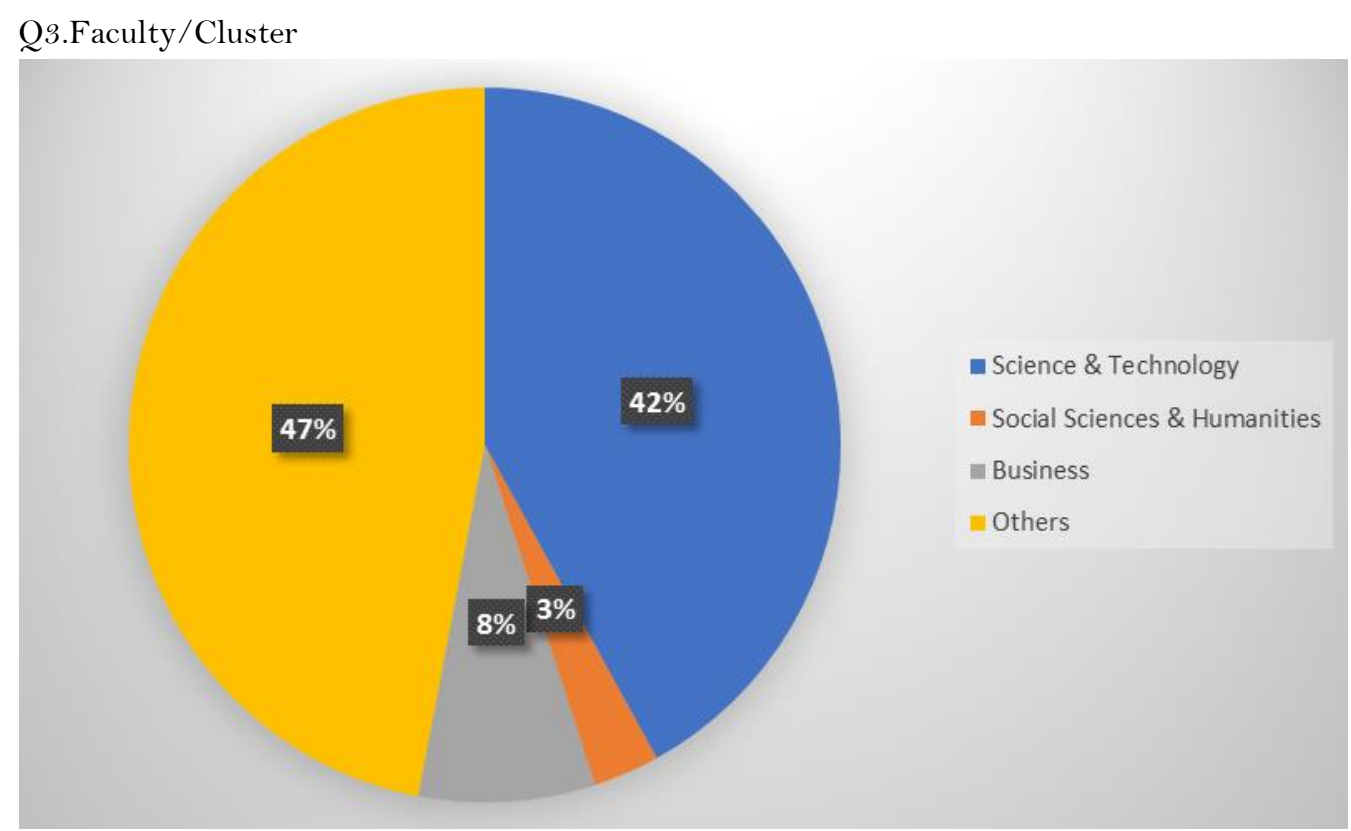

Figure-5. Percentage for Cluster.

Among the respondents in this study Figure 5, 42\% were in the field or cluster of science and technology, 3\% from social sciences and humanities while only $8 \%$ are from business. While $47 \%$ from other fields. 


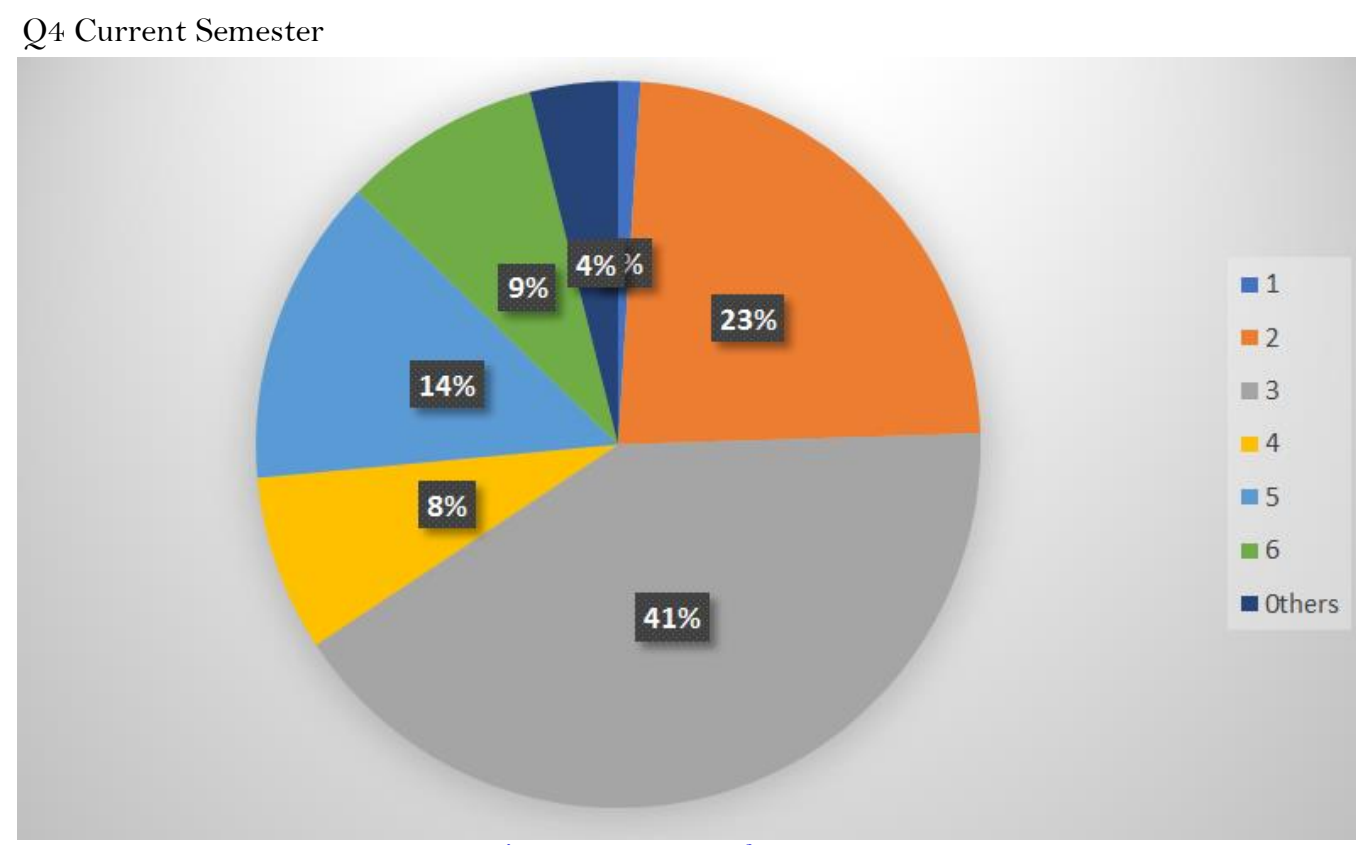

Figure-6. Percentage for semester.

The breakdown of respondents Figure 6 consisted of $1 \%$ from semester 1, 24\% from semester 2 while respondents from semester 3 amounted to $42 \%$. Meanwhile, 4,5 and 6 were represented by $8 \%, 14 \%$ and $9 \%$ of the total respondents in the study, respectively.

\subsection{Findings for Behavioural Factors Portrayed through Social Presence}

This section presents data to answer Research Question 1: How do behaviour factors influence online presence? The behavioural factors of learners during online learning is evident when there is social presence. Social presence in this study is referring to the online presence that students perceived during online learning. It represents behaviour factors as described in SCT (Bandura, 1986). Social presence can be evident through (a) affective expression, b) open communication, and c) group cohesion.

(a) Affective Communication

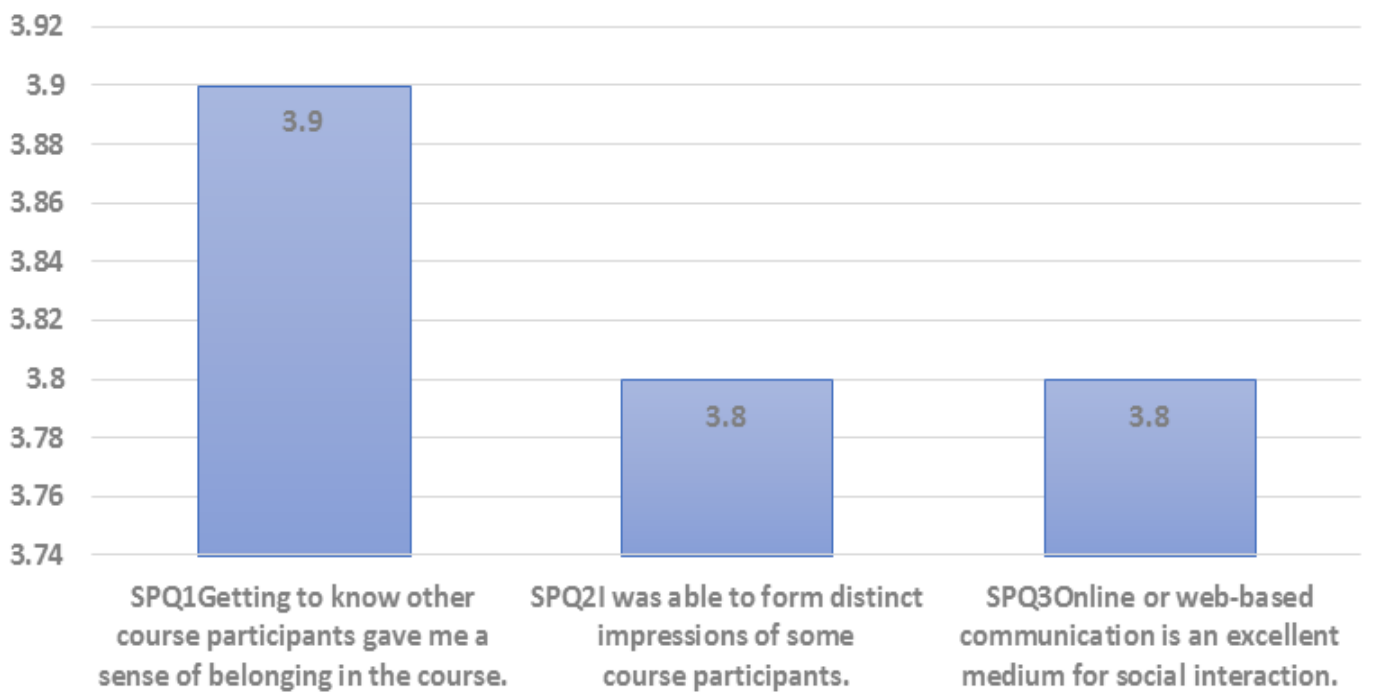

Figure-7. Mean for Affective Factors.

According to Figure 7, the mean obtained is 3.9 when the participants were asked to rate that getting to know other course participants gave them a sense of belonging in the course. Besides, the mean is 3.8 for other questions 
related to the affective communication; when the students are required to rate that they was able to form distinct impressions of some course participants and whether the online or web-based communication is an excellent medium for social interaction.

(b) Mean for Open Communication

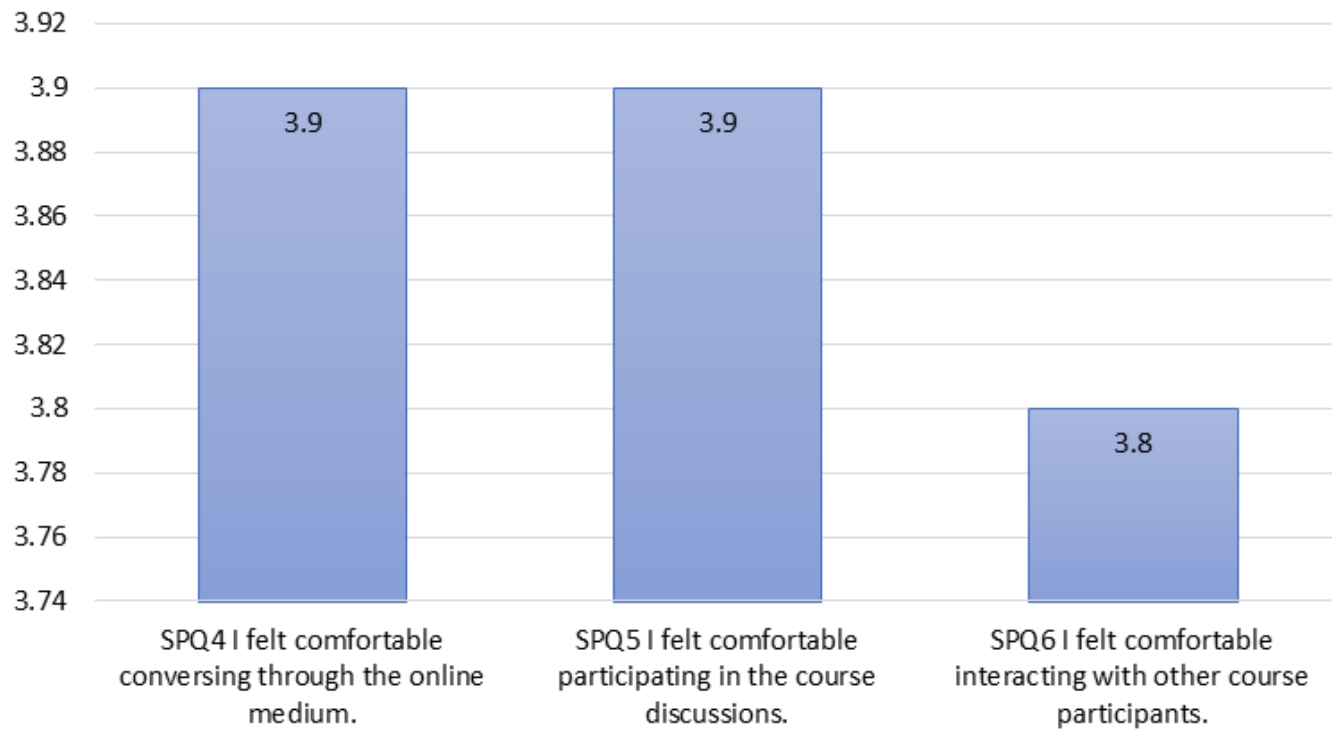

Figure-8. Mean for open communication.

For Figure 8, The highest mean of 3.9 are obtained when the participants were asked whether they felt comfortable conversing through the online medium and participating in the course discussions. The mean is not that much different when asked whether the participants felt comfortable interacting with other course participants (3.8).

(c) Group Cohesion



Figure 9 demonstrate the findings from the aspect of group cohesion, where the participants were asked how they felt in specific conditions during ODL. This is including whether they felt that their point of view was acknowledge by other course participants (SPQ7), or even felt comfortable disagreeing with other course participants while maintaining a sense of trust (SPQ8). The sense of trust is a big subject to be discussed. However, maintaining a sense of trust is needed in order to ensure the group cohesion. The participants were also asked whether the online discussions helped them to develop a sense of collaboration. The mean score for SPQ7 is 3.5, for SPQ8 is 3.6 while for SPQ9 is 3.8 . 


\subsection{Findings for Cognitive Factors via Cognitive Presence}

This section presents the answer to Research Question 2: How do social factors influence online presence? Cognitive presence during online learning can be sparked by (a) triggering events, (b) exploration , (c) integration and (d) resolution.

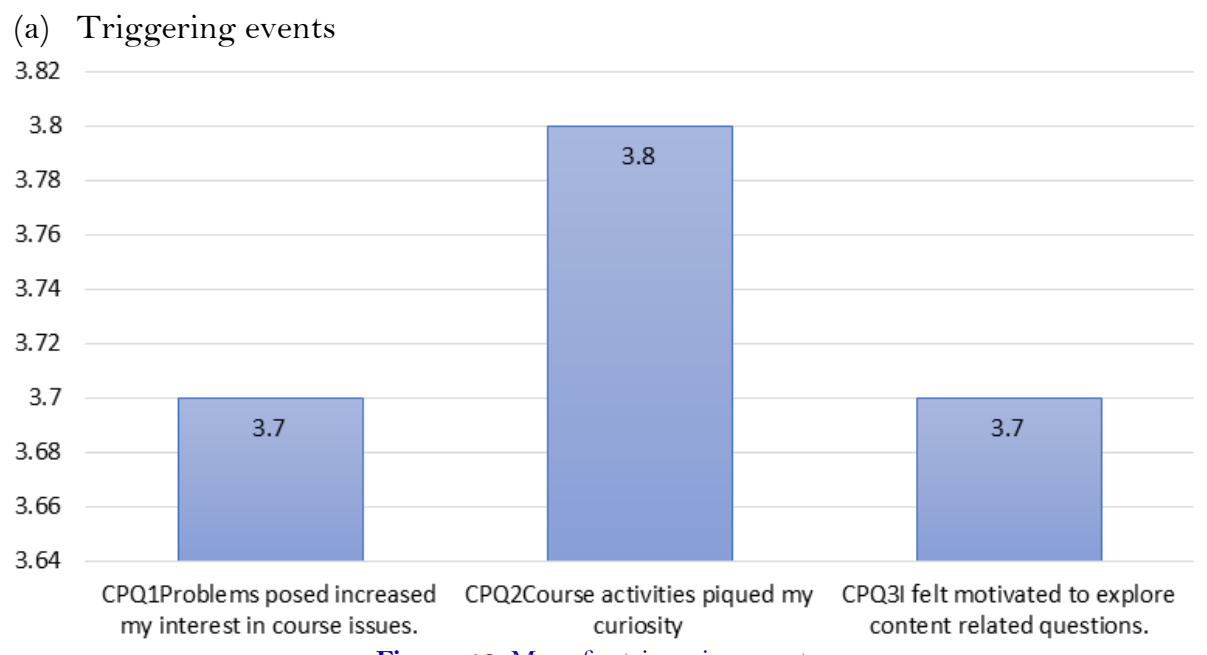

Figure-10. Mean for triggering events.

Figure 10 illustrates the triggering event of three items of cognitive presence. It gives information about the mean for three items of triggering event. The highest mean is 3.8 for the triggering events where the course activities piqued their curiosity. Besides, the mean obtained is 3.7 when the participants were asked whether during the online learning, the problems posed increased their interest in course issues, and how can the participants rate how can they felt motivated to explore content related questions.

(b) Exploration



Figure-11. Mean for Exploration.

Figure 11 illustrates the exploration of three items of cognitive presence. It gives information about the mean for three items of exploration. The highest mean of 3.9 are obtained for item where brainstorming and finding relevant information helped the participants resolve content related questions and online discussions were valuable in helping them appreciate different perspectives. On the other hand, the students which are the participants utilized a variety of information sources to explore problems posed in this course with the mean of 3.8 . 
(c) Integration

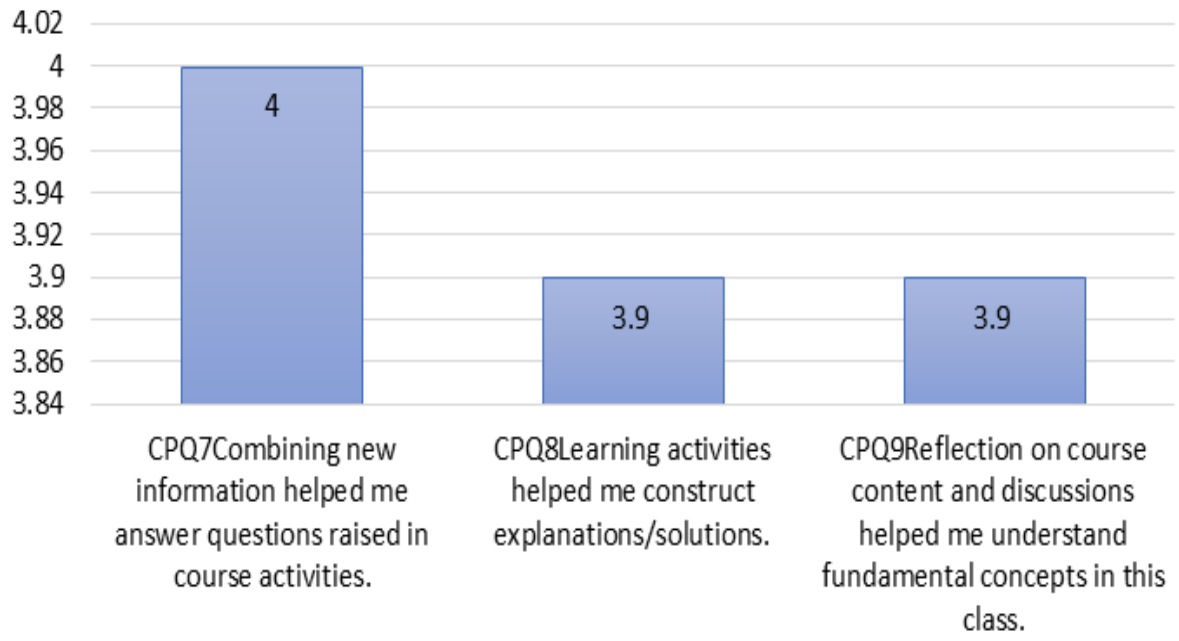

Figure-12. Mean for Integration.

Figure 12 illustrates the integration of three items of cognitive presence. It gives information about the mean for three items of integration. The highest mean of 4 was obtained from the item regarding the combining new information helped the participants answer questions raised in course activities. Besides, the mean 3.9 were obtained for other items that illustrates the integration of cognitive presence; learning activities helped them construct explanations or solutions, and item regarding the reflection on course content and discussions helped them understand fundamental concepts in the class.

(c) Resolution

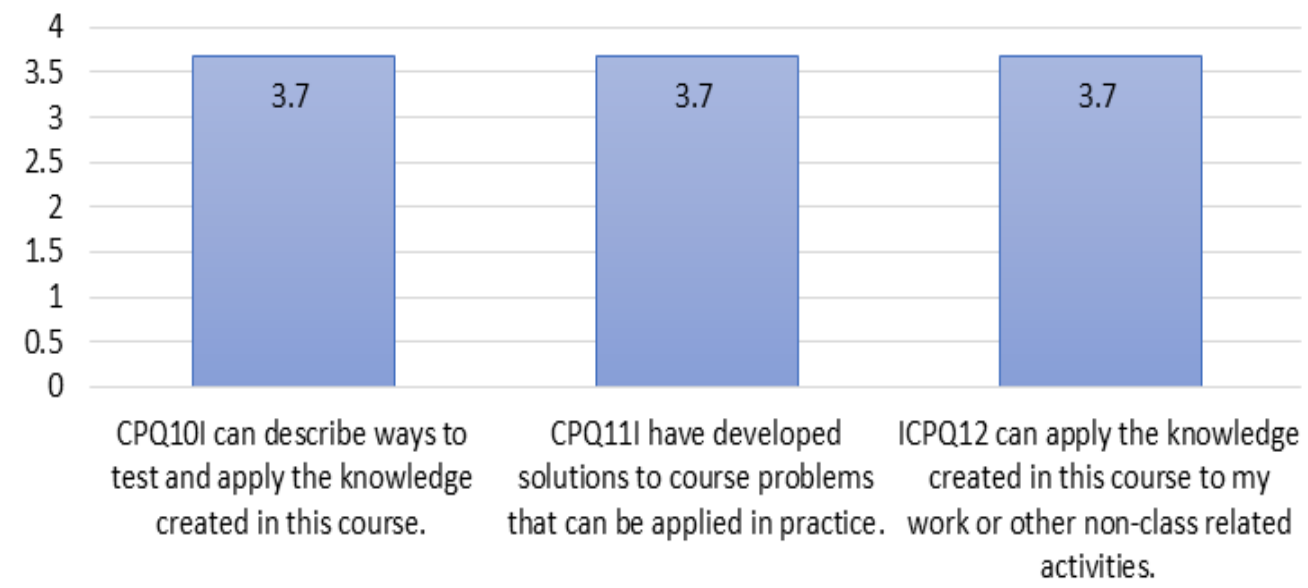

Figure-13. Mean for Resolution

Figure 13 illustrates the resolution of three items of cognitive presence. It gives information about the mean for three items of resolution. Since the mean value for these three items have means of 3.7, it can be concluded that the resolution of all the three items of cognitive presence shown similar level of opinion rated by the students from the perspective of their cognitive presence.

\subsection{Findings for Situational Factors Portrayed through Teaching Presence}

This section presents data to answer Research Question 3: How do situational factors influence online presence? The teachers' presence during online learning can help to create a conducive situational factors needed for learning. The factors involved are (a) design \& organization, (b) facilitation, and (c) direct instruction. 
(a) Design \& Organisation

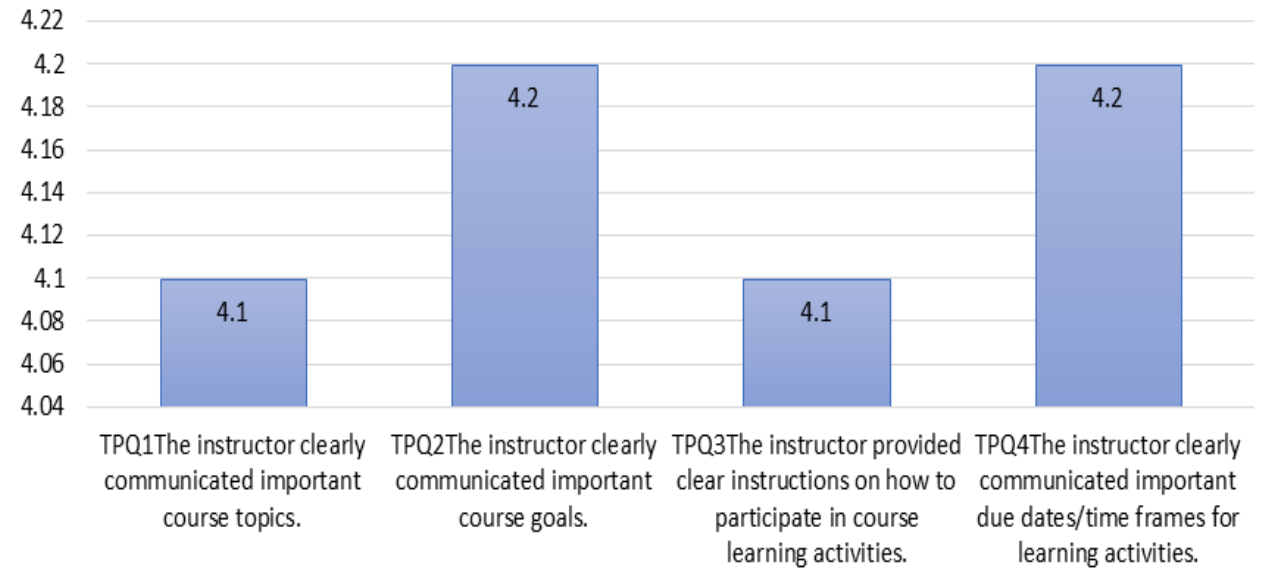

Figure-14. Mean for design and organisation.

Figure 14 illustrates the design and organization of four items of teaching presence. It gives information about the mean for four items of design and organization. The highest mean is reported for item TPQ 2 and TPQ4 which is 4.2 for item where the instructor clearly communicated important due dates or time frames for learning activities and important course goals. Slightly lower mean of 4.1 were obtained for the other two items; the instructor provided clear instructions on how to participate in course learning activities and important course topics.

(b) Facilitation

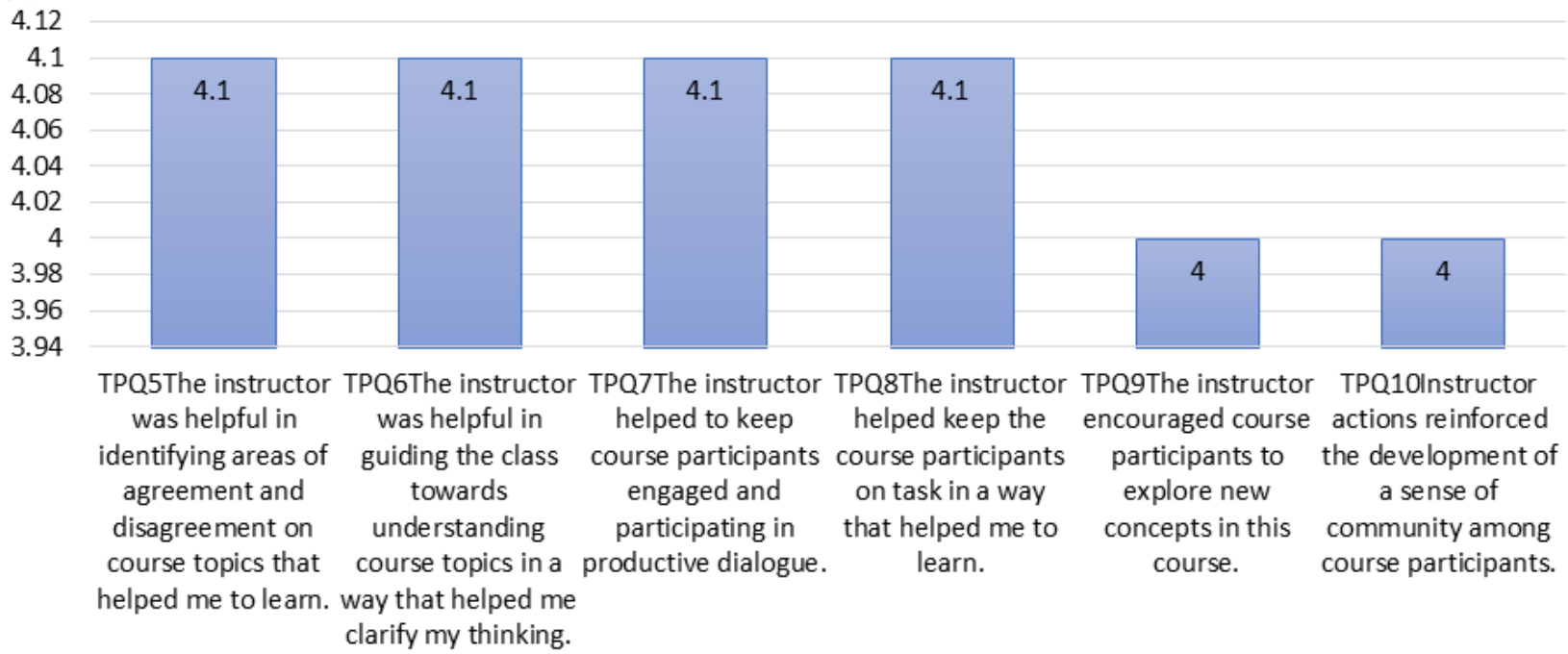

Figure-15. Mean for Facilitation.

Figure 15 shows the facilitation in six items of teaching presence. It gives information about the mean for six items of facilitation.

The mean of 4.1 were obtained for four items regarding; "instructor was helpful in identifying areas of agreement and disagreement on course topics that helped me to learn", "instructor was helpful in guiding the class towards understanding course topics in a way that helped me clarify my thinking", "instructor was helpful in guiding the class towards understanding course topics in a way that helped me clarify my thinking", "instructor helped to keep course participants engaged and participating in productive dialogue", and "instructor helped keep the course participants on task in a way that helped me to learn” according to the participants. 
(c) Direct Instruction

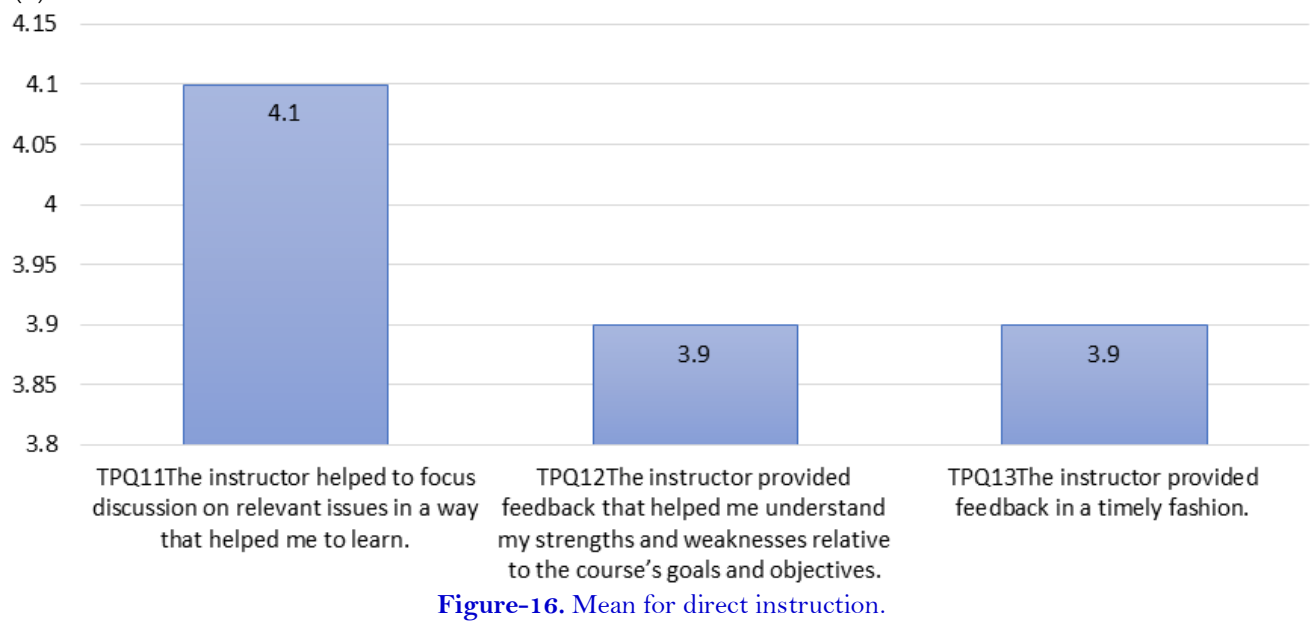

Figure 16 illustrates the direct instruction of three items of teaching presence. It gives information about the mean for three items of direct instruction. The highest mean was obtained when the participants were asked about the instructor helped to focus discussion on relevant issues in a way that helped them. The lowest mean regarding direct instruction where the mean is 3.9 were obtained when the instructor provided feedback in a timely fashion and feedback that helped them understand their strengths and weaknesses relative to the course's goals and objectives.

\section{CONCLUSION}

\subsection{Summary of Findings and Discussion}

Open communication participation in the class discussions can also be done online. Example of the tools that can be used are including padlet, trello, and Google Classroom. UiTM have its own platform called UFUTURE. The creation of virtual groups can help them. The mean values obtained shows that for open communication, the range of scores obtained from students was presented in findings. Next, Interestingly, online discussions helped them to even develop a sense of collaboration trust even though never met before. The comfortable to disagree during online platform shows that the online communication gap can possibly be reduced. Maintaining the personal connections can be a challenging task, however, the findings in paper suggested that online communications and collaborations is still one of the reliable alternatives especially during pandemic. Cognitive engagement is the cognitive processes that enable the user or in this case the students to absorb knowledge. It involves engaging curiosity, focusing attention, flow and concentration (Kemp, Palmer, \& Strelan, 2019). The state of flow and deep involvement refers to the concentration in a single activity while not paying attention to other things at all (Kemp et al., 2019; Saadé \& Bahli, 2005). Students' and instructors' engagement is essential to any institution including university despite face-to-face, hybrid learning or ODL. Self-efficacy which is based mainly from the Social Cognitive Theory (Bandura, 1977) mentioned that efficacy expectations and previous experiences contribute to selfefficacy where "individuals are regarded as proactive agents in the regulation of their cognition, motivation, actions and emotions" (Mayer, 2002). Self-efficacy can be a factor in perceived behaviour control because it relates to the effort, capability and situation which influence usage of educational technology (Aguilera-Hermida, 2020).

Next, cognitive presence are also studied by Grinschgl, Meyerhoff, and Papenmeier (2020) and they called it as cognitive offloading when using mobile devices. It reduces internal cognitive demands due to the externalization of cognitive processes, therefore reducing the use of internal cognitive demands. Further studies required to prove whether it is bad or good for students' cognitive in overall.

How do behaviour or social factors influence online presence? Online presence can be specified as the behaviour which consciously involve, attend, or at least listen, during the online classes using the required online learning 
platform by the instructor during ODL with students. Behaviour intention to use can contribute to the students' intention to take an action and can be used as a predictor (Tajudeen, Madarsha, Suryani, \& Badariah, 2011) even though they might not really perform the behavior as desired in the end. Social factors can be linked to the students' feeling of satisfaction and happiness, or dissatisfaction, stress, and any other mental health issues. According to Perlman et al. (2020) psychological needs of "relatedness refers to a feeling of social connection and belongingness with others". The social factors are important as it is essential to human life; not online the students but also the instructors. The influence of organizational culture and leadership style on instructors' satisfaction, motivation and commitment are addressed by Al-Sada, Al-Esmael, and Faisal (2017) and the instructors' satisfaction (Hanaysha, 2016; Moradi, Almutairi, Idrus, \& Emami, 2013). The concept of technology leadership can play a role as a part of social factors that can influence online presence during ODL. Mallat, Rossi, Tuunainen, and Oorni (2006) concluded that the influence varies depending on the situational factor on where the online platform system is used. During the emergence of COVID-19 pandemic, there are no other choices to teach and learn except through online platforms. This can possibly relate to the reasons of the findings in cognitive presence as well.

\subsection{Pedagogical Implications and Suggestions for Future Research}

Future studies using a mixed methods research design will be more capable of deeper insights research design that tracks the learning activities time should be undertaken to expand the findings and better information in online learning pedagogical development. Additional studies using objective measures, such as the number of students' responses in the discussions and using different contexts of learning style such as flipped learning and collaborative learning are needed to validate the mix method of learning in an online class .

There are many other different types of motivation relate to the engagement dimensions between instructor and students need to be discussed in the framework comprehensively, to investigate the roles of different types of motivation towards the level of student engagement in online learning. More rigorous experimental designs including use only certain group of students to confirm the effectiveness of online teaching and learning process, should be consider in future research. Furthermore, cultural differences among respondents or students need to be consider as a factor influencing the effectiveness of online class and it is recommended to examine how cultural differences affect students' perceived needs and engagement in online class during the pandemic.

Funding: The authors would like to acknowledge the financial support by Universiti Teknologi MARA Cawangan Johor Kampus Segamat under grant Geran Bestari Fasa2/2020 letter number 600-UiTMCJ (PJIA. 5/2) August 2020 - January 2022.

Competing Interests: The authors declare that they have no competing interests.

Acknowledgement: All authors contributed equally to the conception and design of the study.

\section{REFERENCES}

Abbasi, S., Ayoob, T., Malik, A., \& Memon, S. I. (2020). Perceptions of students regarding E-learning during Covid-19 at a private medical college. Pakistan Journal of Medical Sciences, 36(COVID19-S4), S57-S61. Available at: https://doi.org/10.12669/pjms.36.COVID19-S4.2766.

Aboagye, E., Yawson, J. A., \& Appiah, K. N. (2021). COVID-19 and E-learning: The challenges of students in tertiary institutions. Social Education Research, 2(1), 1-8. Available at: https://doi.org/10.37256/ser.122020422.

Adnan, M., \& Anwar, K. (2020). Online learning amid the COVID-19 pandemic: Students' perspectives. Online Submission, 2(1), 45-51. Available at: https://doi.org/10.33902/jpsp.2020261309.

Agarwal, S., \& Kaushik, J. S. (2020). Student's perception of online learning during COVID pandemic. The Indian Journal of Pediatrics, 87(7), 554-554. 
Aguilera-Hermida, A. P. (2020). College students' use and acceptance of emergency online learning due to COVID-19. International Journal of Educational Research Open, 1, 100011. Available at: https://doi.org/10.1016/j.ijedro.2020.100011.

Ajzeen, I. (2008). Consumer attitudes and behavior. In Handbook of Consumer Psychology (1st ed., Vol. 4, pp. 525-548). New York: Routledge.

Al-Rahmi, W., M., Alsayed, A. O., Al-kumaim, N. H., Abualrejal, H., Fazea, Y., \& Al-Maatouk, Q. (2019). Students' satisfaction of E-learning using decision support system (DSS). International Journal of Recent Technology and Engineering (IRTE), 8(4).

Al-Sada, M., Al-Esmael, B., \& Faisal, M. N. (2017). Influence of organizational culture and leadership style on employee satisfaction, commitment and motivation in the educational sector in Qatar. EuroMed Journal of Business, 12(2), 163188. Available at: https://doi.org/10.1 108/EMJB-02-2016-003.

Ali, W. (2020). Online and remote learning in higher education institutes: A necessity in light of COVID-19 pandemic. Higher Education Studies, 10(3), 16-25. Available at: https://doi.org/10.5539/hes.v 10n3p16.

Arbaugh, J. B. (2008). Does the community of inquiry framework predict outcomes in online MBA courses? The International Review of Research in Open and Distributed Learning, 9(2), 1-21. Available at: https://doi.org/10.19173/irrodl.v9i2.490.

Baber, H. (2020). Determinants of students' perceived learning outcome and satisfaction in online learning during the pandemic of COVID-19. Journal of Education and e-Learning Research, 7(3), 285-292. Available at: https://doi.org/10.20448/JOURNAL.509.2020.73.285.292.

Baloran, E. T., Hernan, J. T., \& Taoy, J. S. (2021). Course satisfaction and student engagement in online learning amid COVID19 pandemic: A structural equation model. Turkish Online Journal of Distance Education (TOJDE), 22(2), 1-18.

Bandura, A. (1977). Self-efficacy: Toward a unifying theory of behavioral change. Psychoogical Inquiry, 84(2), 191-215. Available at: https://doi.org/10.1037//0033-295X.

Bandura, A. (1986). Social foundations of thought and action: A social cognitive theory (pp. 617). Englewood Cliffs, New Jersey: Prentice-Hall, Inc.

Davis, F. D. (1989). Perceived usefulness, perceived ease of use and user acceptance of information technology. MIS Quarterly, 13(19), 319-340. Available at: https://www.jstor.org/stable/249008.

Dewantoro, A., \& Rachmawati, I. (2020). Analysis of evaluation and exploratory studies on student's resilience of online learning during pandemic of Covid-19. KONSELI J. Bimbing. Dan Konseling (E-J.), 7(2), 155-162. Available at: https://doi.org/10.24042/kons.v7i2.7422.

Dhawan, S. (2020). Online learning: A panacea in the time of COVID-19 crisis. Journal of Educational Technology Systems, 49(1), 522. Available at: https://doi.org/10.1177/0047239520934018.

Fatonia, N. A., Nurkhayatic, E., Nurdiawatid, E., Fidziahe, G. P., Adhag, S., Irawanh, A. P., . . Azizik, E. (2020). University students online learning system during Covid-19 pandemic: Advantages, constraints and solutions. Systematic Revieres in Pharmacy, 11(7), 570-576.

Ferri, F., Grifoni, P., \& Guzzo, T. (2020). Online learning and emergency remote teaching: Opportunities and challenges in emergency situations. Societies, 10(4), 1-18. Available at: https://doi.org/10.3390/soc10040086.

Garrison, D. R., \& Arbaugh, J. B. (2007). Researching the community of inquiry framework: Review, issues, and future directions. Internet and Higher Education, 10(3), 157-172. Available at: https://doi.org/10.1016/j.iheduc.2007.04.001.

Ghazali, A. F., Sokman, Y., Zakaria, N. B., Majid, M., Mohd Yusoff, R., Shamsuddin, S., \& Moktar, N. (2020). Challenges for education in post-COVID-19 pandemic: A review on managing retrenchment, unemployment and crime.

Ghazali. (2021). Online and distance learning and hybrid learning in COVID-19 era: The effects of pandemic to undergraduate students. International Journal of Learning and Development, 11(2). Available at: https://doi.org/10.5296/ijld.v1 1i2.18666.

Goh, C., Leong, C., Kasmin, K., Hii, P., \& Tan, O. (2017). Students' experiences, learning outcomes and satisfaction in e-learning. Journal of E-learning and Knowledge Society, 13(2). 
Grinschgl, S., Meyerhoff, H. S., \& Papenmeier, F. (2020). Interface and interaction design: How mobile touch devices foster cognitive offloading. Computers in Human Behavior, 108, 106317. Available at: https://doi.org/10.1016/j.chb.2020.106317.

Hanaysha, J. (2016). Determinants of job satisfaction in higher education sector: Empirical insights from Malaysia. International Journal of Human Resource Studies, 6(1), 129-146. Available at: https://doi.org/10.5296/ijhrs.v6i1.9199.

Hiranrithikorn, P. (2019). Advantages and disadvantages of online learning. Paper presented at the In International Academic Multidisciplinary Research Conference In Berlin 2019.

Kemp, A., Palmer, E., \& Strelan, P. (2019). A taxonomy of factors affecting attitudes towards educational technologies for use with technology acceptance models. British Journal of Educational Technology, 50(5), 2394-2413. Available at: https://doi.org/10.1111/bjet.12833.

Kokoc, M. (2019). Flexibility in e-learning: Modelling its relation to behavioural engagement and academic performance. Themes in eLearning, 12(12), 1-16.

Kulal, A., \& Nayak, A. (2020). A study on perception of teachers and students toward online classes in Dakshina Kannada and Udupi District. Asian Association of Open Universities Journal, 15(3), 285-296. Available at: https://doi.org/10.1108/AAOUJ-07-2020-0047.

Maatuk, A. M., Elberkawi, E. K., Aljawarneh, S., Rashaideh, H., \& Alharbi, H. (2021). The COVID-19 pandemic and E-learning: challenges and opportunities from the perspective of students and instructors. Journal of Computing in Higher Education, 1-18. Available at: https://doi.org/10.1007/s12528-02 1-09274-2.

Mallat, N., Rossi, M., Tuunainen, V. K., \& Oorni, A. (2006). The impact of use situation and mobility on the acceptance of mobile ticketing services, in System Sciences, 2006, HICSS'06. Paper presented at the Proceedings of the 39th Annual Hawaii International Conference, IEEE.

Mayer, R. E. (2002). Multimedia learning. Psychol Learning and Motivation, 41(1), 85-139.

Moradi, E., Almutairi, D. O., Idrus, D., \& Emami, R. (2013). The influence of organizational learning culture on job satisfaction among academic staff. Journal of Global Management, 5(1), 56-66.

Muilenburg, L., Y., \& Berge, Z. L. (2005). Student barriers to online learning: A factor analytic study. Distance Education, 26(1), 29-48. Available at: https://doi.org/10.1080/01587910500081269.

Mukhtar, K., Javed, K., Arooj, M., \& Sethi, A. (2020). Advantages, limitations and recommendations for online learning during COVID-19 pandemic era. Pakistan Journal of Medical Sciences, 36(COVID19-S4), 1-15. Available at: https://doi.org/10.12669/pjms.36.covid19-s4.2785.

Perlman, D., Moxham, L., Patterson, C., Cregan, A., Alford, S., \& Tapsell, A. (2020). Mental health stigma and undergraduate nursing students: A self-determination theory perspective. Collegian, 27(2), 226-231. Available at: https://doi.org/10.1016/j.colegn.2019.08.001.

Rogers, E. M. (1995). Diffusion of Innovations: Modifications of a model for telecommunications, In Die Diffusion von Innovationen in der Telekommunikation 1995 (pp. 25-38). Berlin, Heidelberg: Springer.

Saadé, R., \& Bahli, B. (2005). The impact of cognitive absorption on perceived usefulness and perceived ease of use in on-line learning: An extension of the technology acceptance model. Information \& Management, 42(2), 317-327. Available at: https://doi.org/10.1016/j.colegn.2019.08.001.

Subramanian, A., Timberlake, M., Mittakanti, H., Lara, M., \& Brandt, M. L. (2012). Novel educational approach for medical students: Improved retention rates using interactive medical software compared with traditional lecture-based format. Journal of Surgical Education, 69(4), 449-452. Available at: https://doi.org/10.1016/j.jsurg.2012.05.013.

Tajudeen, S., K., Madarsha, B. N., Suryani, N., \& Badariah, T. A. T. (2011). Investigating students' attitude and intention to use social software in higher institution of learning in Malaysia. Multicultural Education \& Technology Journal, 5(3), 194208.

Tareen, H., \& Haand, M. T. (2020). A case study of UiTM post-graduate students' perceptions on online learning: Benefits \& challenges. International Journal of Advanced Research and Publications, 4(6), 86-94. 
Tornatzky, L. G., \& Klein, K. J. (1982). Innovation characteristics and innovation adoption-implementation: A meta-analysis of findings. IEEE Transactions on Engineering Management, 29(1), 28-45. Available at: https://doi.org/10.1109/tem.1982.6447463.

Venkatesh, V., Morris, M. G., Davis, G. B., \& Davis, F. D. (2003). User acceptance of information technology: Toward a unified view. MIS Quarterly, 27(3), 425-478. Available at: https://doi.org/10.2307/30036540.

Yusuf, B., \& Jihan, A. (2020). Are we prepared enough? A case study of challenges in online learning in a private higher learning institution during the Covid-19 outbreaks. Advances in Social Sciences Research Journal, 7(5), 205-212. Available at: https://doi.org/10.14738/assrj.75.8211.

Views and opinions expressed in this article are the views and opinions of the author(s), International Journal of Asian Social Science shall not be responsible or answerable for any loss, damage or liability etc. caused in relation to/arising out of the use of the content. 